\title{
BMJ Open Exploring the potential impact of rotavirus vaccination on work absenteeism among female administrative personnel of the City of Antwerp through a retrospective database analysis
}

\author{
Baudouin Standaert, ${ }^{1}$ Els Van de Mieroop, ${ }^{2}$ Vera Nelen ${ }^{2}$
}

To cite: Standaert B, Van de Mieroop E, Nelen V.

Exploring the potential impact of rotavirus vaccination on work absenteeism among female administrative personnel of the City of Antwerp through a retrospective database analysis. BMJ Open 2015;5: e007453. doi:10.1136/ bmjopen-2014-007453

- Prepublication history for this paper is available online. To view these files please visit the journal online (http://dx.doi.org/10.1136/ bmjopen-2014-007453).

Received 16 December 2014 Revised 29 April 2015 Accepted 12 May 2015

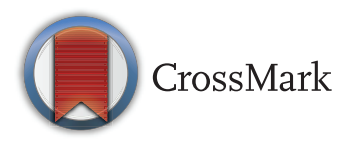

${ }^{1}$ Department of Health Economics, GSK Vaccines, Wavre, Belgium

${ }^{2}$ Department of Public Health, Provincial Institute of Hygiene, Antwerp, Belgium

Correspondence to Dr Baudouin Standaert; baudouin.a.standaert@gsk. com

\section{ABSTRACT}

Objectives: Rotavirus vaccination has been reimbursed in Belgium since November 2006 with a high uptake (>85\%). Economic analyses of the vaccine have been reported, including estimates of indirect cost gain related to the reduction in work absenteeism. The objective of this study was to evaluate the latter parameter using real-life data.

Design and setting: A simple model estimated the reduction in absent workdays per working mother with a firstborn baby after the introduction of the rotavirus vaccine. Next, data on work absences were retrospectively analysed (from 2003 to 2012) using a database of administrative employees $(n=11600$ working women per year) in the City of Antwerp. Observed reductions in absenteeism after the introduction of the vaccine were compared with the results from the model. These reductions would most likely be observed during the epidemic periods of rotavirus (from January to the end of May) for short-duration absences of $\leq 5$ days. We compared data from outside epidemic periods (from June to December), expecting no changes over time prevaccine and postvaccine introduction, as well as with a control group of women aged 30-35 years with no first child.

Results: Model estimates were 0.73 working days gained per working mother. In the database of the City of Antwerp, we identified a gain of 0.88 working days during the epidemic period, and an accumulated gain of 2.24 days over a 3-year follow-up period. In the control group, no decrease in absenteeism was measured. Giving vaccine access to working mothers resulted in an estimated accumulated net cost gain of $€ 187$ per mother. Conclusions: Reduction in absenteeism among working mothers was observed during periods of the epidemic after the introduction of the rotavirus vaccine in Belgium. This reduction is in line with estimates of indirect cost gains used in economic evaluations of the rotavirus vaccine.

Trial registration number: $\mathrm{HO}-12-12768$.

\section{Strengths and limitations of this study}

- Economic models of rotavirus vaccination simulate the absence from work due to rotavirus infection in children as well as the reduction in work absenteeism of mothers due to vaccine introduction, but nobody has evaluated these reductions in a real-life setting.

- The objective of this study was to evaluate the impact of introducing the rotavirus vaccine in Belgium on the reduction in work absenteeism over an observation period of 9 years (from 2003 to 2012), using real-life data from a database of administrative personnel in the City of Antwerp. The vaccine was introduced with a high uptake in November 2006.

- The analysis suggests that rotavirus vaccination resulted in a reduction of absences from work among mothers with a first child during the first, second and third epidemic periods of rotavirus after birth, with a cumulative gain of 2.24 days per woman.

- This translated into a net cost gain for the employer of $€ 187$ per working mother.

- The main limitation of the study is that the results are based on retrospective data analysis with no causal relationship between the introduction of the vaccine and the reduction in absenteeism specified. However, several indirect arguments have been brought forward to support the potential link.

\section{INTRODUCTION}

The rotavirus (RV) epidemic is an annual recurrent public health problem of severe diarrhoea in young children, with a peak incidence before the age of 2 years. ${ }^{1}{ }^{2} \mathrm{RV}$ disease preferentially occurs during the winter months in temperate countries in the northern hemisphere. The virus spreads 
among young children but may manifest a higher rate of transmission at around 10 months of age, because at this age a child in a day-care centre is a conducive virus transmitter to younger and older children. ${ }^{3}$

RV vaccination was introduced in Belgium in November 2006 as a new management strategy against the illness. ${ }^{4}$ Belgium was one of the first countries in Europe to integrate this vaccine into its routine childhood immunisation programme. ${ }^{5}$ Vaccine uptake was high from the start $(>85 \%)$ because it was recommended by the High Committee of Health Promotion. Moreover, the organisational structure for implementing immune protection in children and a good follow-up process are both well developed in the country. ${ }^{6}$

Several economic evaluations of the RV vaccine have been conducted and most of these analyses have included indirect cost estimates. ${ }^{7-10}$ An analysis of the financial burden of RV disease in four European countries indicated that the indirect costs could be substantial: half of the total cost of the disease per child at risk could be linked to these indirect costs. ${ }^{11}$ However, until now, these estimates have always been simulated and nobody has been able to evaluate the reduction of work absenteeism using real-life data subsequent to the introduction of the RV vaccine. ${ }^{12}$ Obtaining that type of evidence is not easy, as we need to have an environment where employment is stable among a large number of employees in order to follow enough working mothers with young children under the same working conditions and having the same exposure to the disease. In addition, we needed to obtain detailed information on each period of absenteeism with a start and end date linked to the employee's family condition when a new child is born. The data should be available over a long enough period of time (at least 5 years) and in electronic format with easy access, so that the time periods before and after vaccine introduction can be analysed and compared.

It was postulated that during epidemic periods of RV disease, working mothers with a first child would be absent from work for short durations ( $\leq 5$ days) more often than during non-epidemic periods or after the introduction of the vaccine. ${ }^{13}$ In addition, working women with no exposure of children to the rotavirus disease should not experience any reduction in work absenteeism as a result of the vaccine. We first constructed a simple model that could give us guidance in our search for parameters in real-life data sets.

\section{DESIGN AND SETTING}

\section{Simple model construction}

The simple model calculates the expected difference in worker absenteeism when comparing exposure versus non-exposure to the RV vaccine. It is expressed as the estimated number of days per year and per working mother with a first child. The value estimated would then serve as a benchmark for analysing the observed data.

\section{Observed data}

We selected a database from the City of Antwerp which has a sufficient number of subjects from the target group ( $\mathrm{n} \approx 11600$ women per year) over a long period of time (from 2003 to 2012). This database collects detailed information on absences from work for all its administrative personnel, including the general reason, duration and time period of the absence (start and end dates). It was unfortunate that electronic data before 2003 were not available in order to better capture overall trend results related to the disease over time. The data are reasonably accurate because personnel payment is linked to that system. Moreover, through a unique subject number, the database could be linked to other databases in the city which compile information on family composition and the birth dates of children born to each employee. The data were made available after decoding subjects to prevent identification of individuals and after approval of the project and its objectives by the administrative head of the city.

We performed the analysis in three steps. First, to increase the chances of observing a difference in absenteeism due to vaccination, we selected a target group of women with a first child approximately 10 months of age during the typical RV epidemic season (January-May) of each year. These children are known transmitters of the virus. In a second step, we conducted an annual analysis of the same working mothers but with a first child born any time during the year prior to the next epidemic period. We expected a larger difference (ie, less absenteeism) from the first analysis than from the second one. In a third step, we selected from the same database women aged 30-35 years with no first child, but working during the same observation period from 2004 to 2012, from January to May. It was hypothesised that these women, considered as a control group, should not benefit from the rotavirus vaccination, and therefore we would not observe any decrease in work absenteeism over time.

Thus, in the first step, we selected working women with a first child born during the months of April to July on a yearly basis from 2003 to 2011. That number was variable per year. We then recorded short absences from work ( $\leq 5$ days) which were registered 10 months after the birth of their child. A maximum of 5 days of absence was considered the right limit to be linked to the disease event that is frequent enough to occur and should not interfere with planned holiday periods. A longer period of absenteeism, such as $\leq 10$ days, could be considered a holiday and therefore become a confounding factor in the analysis. The period of 10 months postpartum was equal to the normal RV epidemic season. The sum of all work absences during that annual period of time in all years from 2004 to 2012 was then divided by the number of mothers considered during the previous year in order to obtain an average value per working mother with a first child during the following epidemic period.

We compared the data by year to observe any marked difference in work absenteeism after 2006, which was 
the year RV vaccination was introduced. We also analysed absenteeism data of short duration from the same working mothers outside the epidemic period, expecting a much lower rate and no major change over time. To be able to compare the same values by time period, we analysed the average value by month for each period (epidemic and non-epidemic).

If an important difference was observed in the first step, we then proceeded to the second step of evaluating work absences during each epidemic period among mothers with a first child born any time during the previous year (whole-year birth cohort). We again reported the sum of all days absent from work in the postpartum year during epidemic and non-epidemic periods. We hypothesised that if the difference in absenteeism was large enough in the first step, it should still be present in the second step, and that would facilitate the analysis of other time periods. In addition, we evaluated the same type of absences from work among mothers with a firstborn child in its second and third years of life (eg, absences of mothers with a first child born during 2003 were evaluated in the epidemic periods of 2005 and 2006, respectively). Finally, we compared these observed data with the estimates obtained from the simple model. The control group was analysed in the same way as the other groups. We report the same type of outcome measure over time, which is the average number of days of absence from work per woman during the epidemic period per year.

On the basis of the above results, we could calculate the net cost gain per working mother through the average reduction in absenteeism postvaccination. This was adjusted by the cost of the vaccine, which was considered at $€ 60 /$ dose $^{14}$ The average gross salary for a working mother in the City of Antwerp was estimated at $€ 135 /$ day. ${ }^{15}$

To observe statistically significant differences between prevaccination and postvaccination absenteeism per working mother, we compared the data by ranking mothers into six categories according to the number of days absent from work $(0,1,2,3,4$ and 5 days) during the epidemic period. We then applied a statistical ranking test (Mann-Whitney U-test, with a significance level of $\mathrm{p}<0.05$, two-sided) for the pooled years (2004-2006) prevaccination with the pooled years (2010-2012) postvaccination. We also evaluated for tables 1 and 2 a pooled analysis of the period prevaccination (2004-2006) versus postvaccination (2010-2012) regarding the average days of absenteeism per woman per period with a t test for a statistical significance level of $\mathrm{p}<0.05$, two-sided. Finally, the comparison between the control group (women aged 30-35 years) and the target group (mothers with a first child) was analysed using linear regression analysis over the period of 2004-2012 using year as the independent variable and the average number of days absent from work during the observation period as the dependent variable. The $\beta$ regression coefficients were compared for significant difference between the two groups using a t test comparison for a significance level of $p<0.05$, two sided. Statistical analyses were performed using IBM SPSS Statistics V.22.0 and GraphPad v6.

\section{RESULTS}

\section{Modelled data}

As shown in table 3, the simple model indicated that the introduction of the RV vaccine produced a gain of 0.730.80 working days per mother, with a first child in the vaccinated cohort. Since there was no maximum vaccine coverage in the vaccinated cohort, we needed to include a normal rate of infection among the unvaccinated in that cohort (='Rest'). A sensitivity analysis around that value was performed, since high vaccination levels result in a herd effect in the 'Rest' group. Therefore, the difference between prevaccination and postvaccination absenteeism could be higher.

\section{Observed data}

First-step analysis

Table 1 summarises the annual number of days absent from work in each epidemic season among the target

Table 1 Average number of short work absences per targeted woman with a first child during the epidemic and non-epidemic seasons

\begin{tabular}{|c|c|c|c|c|c|c|c|c|c|c|c|}
\hline \multirow[b]{2}{*}{ Year } & \multirow{2}{*}{$\begin{array}{l}\text { Women in } \\
\text { target } \\
\text { period }\end{array}$} & \multicolumn{5}{|c|}{ Epidemic period (January-May) } & \multicolumn{5}{|c|}{ Non-epidemic period (June-December) } \\
\hline & & $\begin{array}{l}\text { Cumulative } \\
\text { days absent }\end{array}$ & $\begin{array}{l}\text { Per } \\
\text { woman }\end{array}$ & $\begin{array}{l}95 \% \\
\mathrm{Cl}+ \\
\end{array}$ & $\begin{array}{l}95 \% \\
\mathrm{Cl}- \\
\end{array}$ & $\begin{array}{l}\text { Per } \\
\text { month }\end{array}$ & $\begin{array}{l}\text { Cumulative } \\
\text { days absent }\end{array}$ & $\begin{array}{l}\text { Per } \\
\text { woman }\end{array}$ & $\begin{array}{l}95 \% \\
\mathrm{Cl}+\end{array}$ & $\begin{array}{l}95 \% \\
\mathrm{Cl}- \\
\end{array}$ & $\begin{array}{l}\text { Per } \\
\text { month }\end{array}$ \\
\hline 2003 & 56 & & & & & & & & & & \\
\hline 2004 & 57 & 98 & 1.750 & 2.252 & 1.247 & 0.350 & 76 & 1.357 & 1.764 & 0.950 & 0.194 \\
\hline 2005 & 62 & 97 & 1.702 & 2.234 & 1.168 & 0.340 & 27 & 0.474 & 0.742 & 0.204 & 0.068 \\
\hline 2006 & 66 & 98 & 1.581 & 2.048 & 1.113 & 0.316 & 58 & 0.935 & 1.309 & 0.561 & 0.134 \\
\hline 2007 & 80 & 109 & 1.652 & 2.116 & 1.186 & 0.330 & 54 & 0.818 & 1.151 & 0.485 & 0.117 \\
\hline 2008 & 65 & 148 & 1.850 & 2.285 & 1.414 & 0.370 & 67 & 0.838 & 1.136 & 0.538 & 0.120 \\
\hline 2009 & 62 & 65 & 1.000 & 1.346 & 0.653 & 0.200 & 39 & 0.600 & 0.900 & 0.299 & 0.086 \\
\hline 2010 & 96 & 63 & 1.016 & 1.354 & 0.677 & 0.203 & 66 & 1.065 & 1.484 & 0.644 & 0.152 \\
\hline 2011 & 114 & 64 & 0.667 & 0.907 & 0.426 & 0.133 & 68 & 0.708 & 1.049 & 0.491 & 0.101 \\
\hline 2012 & & 98 & 0.860 & 1.113 & 0.588 & 0.172 & 84 & 0.737 & 0.972 & 0.501 & 0.105 \\
\hline
\end{tabular}


Table 2 Frequency distribution of days absent from work prevaccination and postvaccination among mothers with a firstborn child in the first year of life during the epidemic period and the non-epidemic period, and among women aged 30-35 years old with no firstborn child during the epidemic period only

\begin{tabular}{|c|c|c|c|c|c|c|c|c|c|}
\hline Days & 2004 & 2005 & 2006 & 2007 & 2008 & 2009 & 2010 & 2011 & 2012 \\
\hline \multicolumn{10}{|c|}{ Full cohort of women with firstborn child, epidemic period } \\
\hline 0 & 70 & 85 & 78 & 94 & 101 & 116 & 131 & 159 & 167 \\
\hline 1 & 34 & 26 & 32 & 22 & 39 & 54 & 37 & 32 & 41 \\
\hline 2 & 10 & 17 & 14 & 33 & 16 & 22 & 13 & 30 & 19 \\
\hline 3 & 8 & 8 & 14 & 15 & 13 & 14 & 16 & 16 & 10 \\
\hline 4 & 12 & 13 & 11 & 10 & 19 & 8 & 10 & 10 & 11 \\
\hline 5 & 31 & 48 & 31 & 35 & 35 & 13 & 14 & 9 & 17 \\
\hline Total $\mathrm{N}$ & 165 & 197 & 180 & 209 & 223 & 227 & 221 & 256 & 265 \\
\hline Total $\mathrm{N}$ of absent days & 281 & 376 & 301 & 348 & 361 & 237 & 221 & 225 & 238 \\
\hline Average & 1.703 & 1.909 & 1.672 & 1.665 & 1.619 & 1.044 & 1 & 0.879 & 0.898 \\
\hline $95 \% \mathrm{Cl}+$ & 2.005 & 2.201 & 1.955 & 1.924 & 1.873 & 1.264 & 1.236 & 1.09 & 1.116 \\
\hline $95 \% \mathrm{Cl}-$ & 1.401 & 1.617 & 1.389 & 1.406 & 1.365 & 0.825 & 0.764 & 0.668 & 0.68 \\
\hline \multicolumn{10}{|c|}{ Cohort of women aged $30-35$ year, epidemic period } \\
\hline 0 & 248 & 303 & 365 & 399 & 435 & 242 & 440 & 500 & 464 \\
\hline 1 & 179 & 176 & 168 & 191 & 257 & 372 & 167 & 206 & 230 \\
\hline 2 & 106 & 104 & 123 & 109 & 128 & 162 & 109 & 126 & 195 \\
\hline 3 & 63 & 60 & 76 & 79 & 79 & 72 & 101 & 139 & 111 \\
\hline 4 & 61 & 77 & 93 & 81 & 97 & 77 & 65 & 71 & 89 \\
\hline 5 & 157 & 155 & 160 & 215 & 203 & 81 & 144 & 144 & 200 \\
\hline Total N & 814 & 875 & 985 & 1074 & 1199 & 1006 & 1026 & 1186 & 1289 \\
\hline Total $\mathrm{N}$ of absent days & 1609 & 1647 & 1814 & 2045 & 2153 & 1625 & 1668 & 1879 & 2309 \\
\hline Average & 1.977 & 1.882 & 1.842 & 1.904 & 1.796 & 1.615 & 1.626 & 1.584 & 1.791 \\
\hline $95 \% \mathrm{Cl}+$ & 2.106 & 2.008 & 1.96 & 2.021 & 1.903 & 1.711 & 1.74 & 1.688 & 1.892 \\
\hline $95 \% \mathrm{Cl}-$ & 1.847 & 1.757 & 1.724 & 1.787 & 1.689 & 1.519 & 1.512 & 1.481 & 1.691 \\
\hline \multicolumn{10}{|c|}{ Full cohort of women with firstborn child, non-epidemic period } \\
\hline 0 & 96 & 142 & 116 & 129 & 142 & 158 & 142 & 163 & 176 \\
\hline 1 & 25 & 27 & 24 & 32 & 27 & 20 & 29 & 34 & 31 \\
\hline 2 & 22 & 13 & 16 & 19 & 22 & 22 & 13 & 14 & 20 \\
\hline 3 & 5 & 3 & 9 & 16 & 14 & 12 & 13 & 17 & 14 \\
\hline 4 & 8 & 7 & 6 & 9 & 10 & 9 & 6 & 12 & 12 \\
\hline 5 & 9 & 5 & 9 & 4 & 8 & 6 & 18 & 16 & 12 \\
\hline Total N & 165 & 197 & 180 & 209 & 223 & 227 & 221 & 256 & 265 \\
\hline Total $\mathrm{N}$ of absent days & 161 & 115 & 152 & 174 & 193 & 166 & 208 & 241 & 221 \\
\hline Average & 0.976 & 0.584 & 0.844 & 0.833 & 0.865 & 0.731 & 0.941 & 0.941 & 0.834 \\
\hline $95 \% \mathrm{Cl}+$ & 1.203 & 0.801 & 1.07 & 1.026 & 1.063 & 0.931 & 1.156 & 1.136 & 1.023 \\
\hline $95 \% \mathrm{Cl}-$ & 0.749 & 0.367 & 0.618 & 0.639 & 0.668 & 0.532 & 0.727 & 0.746 & 0.645 \\
\hline
\end{tabular}

$\mathrm{N}$, working mothers.

group of working mothers with a first child born between April and July during the previous year. It should be noted that a reduction in absenteeism is observed only after 2008 because the vaccine was introduced in November 2006. In the non-epidemic period, no large changes were seen in any given month. We observed a reduction in absenteeism (average days per woman (2003-2008)-average days per woman (20092012) $=0.821$ ) noted from 2009 onwards, so that we could proceed with the second step. Applying t-testing with unequal variance on a pooled analysis of days being absent from work during the prevaccination period (2004-2006; $\mathrm{n}=175$ observations, average value $=$ 1.674 days) versus the postvaccination period (20102012; $n=272$ observations, average value $=0.827$ days ), the test result of 5.0365 with $\mathrm{df}=283$ was statistically very significant $(\mathrm{p}<0.0001$, two sided) with a mean difference of 0.847 days and $95 \%$ CI of 0.540 to 1.154 days.

\section{Second-step and third-step analyses}

Table 2 reports the number of absent workdays among mothers with a firstborn child during the epidemic period of the first postpartum year in six different categories $(0,1,2,3,4$ and 5 days), together with average values and the $95 \%$ CI. From 2009 onwards, we observed a clear increase in the number of 0-day absences from work and a decline in the number of 5-day absences. In the control group of women aged 30-35 years, no marked change in absenteeism was seen over time. There is not much difference noted in the average values for the full cohort of women (table 2) compared with the targeted cohort (table 1), except for a narrower 
Table 3 Model estimates

\begin{tabular}{|c|c|c|c|}
\hline Parameter & Value & $\begin{array}{l}\text { Absolute } \\
\text { numbers }\end{array}$ & Difference \\
\hline \multicolumn{4}{|l|}{ No vaccination } \\
\hline Working mothers with a 1st child & 75 & & \\
\hline$\%$ of mothers with a 1st child having diarrhoea 1st year & $20 \%$ & $75 \times 20 \%=15$ & \\
\hline $\begin{array}{l}\text { Average duration (days) for being absent for diarrhoea } \\
\text { in a child }\end{array}$ & 5 & $15 \times 5=75$ & \\
\hline Average number of days absent/woman & & $75 / 75=1$ & 1 \\
\hline \multicolumn{4}{|l|}{ Vaccination } \\
\hline Working mothers with a 1st child & 75 & & \\
\hline$\%$ of mothers with a vaccinated child & $85 \%$ & $75 \times 85 \%=64$ & \\
\hline$\%$ of mothers with no vaccinated child & $(1-85 \%)=15 \%$ & $75 \times 15 \%=11$ & \\
\hline Vaccine efficacy against diarrhoea & $85 \%$ & & \\
\hline$\%$ of mothers with a vaccinated child still having diarrhoea & $20 \% \times(100 \%-85 \%)=3 \%$ & $64 \times 3 \%=2$ & \\
\hline $\begin{array}{l}\% \text { of mothers with an unvaccinated child still having } \\
\text { diarrhoea (Rest) }\end{array}$ & $20 \%$ & $11 \times 20 \%=2$ & \\
\hline $\begin{array}{l}\text { Average duration (days) for being absent for diarrhoea } \\
\text { in a child }\end{array}$ & 5 & $4 \times 5=20$ & \\
\hline Average number of days absent/woman & & $20 / 75=0.27$ & 0.27 \\
\hline Gain in working days avoided/woman after vaccination 1st year & & & $(1-0.27)=0.73$ \\
\hline \multicolumn{4}{|l|}{ Sensitivity analysis } \\
\hline $\begin{array}{l}\text { Proportion of children with diarrhoea is lower because of the } \\
\text { vaccine's herd effect in the Rest group }\end{array}$ & $10 \%$ instead $20 \%$ & $11 \times 10 \%=1$ & \\
\hline $\begin{array}{l}\text { Average duration (days) for being absent for diarrhoea } \\
\text { in a child }\end{array}$ & & $3 \times 5=15$ & \\
\hline Average number of days absent/woman & & $15 / 75=0.20$ & 0.20 \\
\hline Gain in working days avoided/woman after vaccination 1st year & & & $(1-0.20)=0.80$ \\
\hline
\end{tabular}

CI in table 2 because of the higher number of persons enrolled in the analysis. During the non-epidemic period, there was no big variation in the numbers noted year after year. Rank testing using the Mann-Whitney U statistics revealed a statistically significant change in distribution of the different day categories for being absent from work ( $\mathrm{n}=1284$ (2004, 2005, 2006, 2010, 2011, 2012); z-statistics $=7.8903 ; \mathrm{p}<0.0001$, two sided) linked to an observed average reduction in days of absence from work over time. Figure 1 reports the percentage change per year of each of the 6-day categories for absence from work, showing a dramatic change in category 0 versus category 5 days during the epidemic period for the target group (figure 1A). This is not observed during the non-epidemic period (figure 1B) or in the control group (figure 1C).

Applying t-testing with unequal variance for the target group during the epidemic period on a pooled analysis of days absent from work during the prevaccination period (2004-2006; $\mathrm{n}=542$ observations, average value $=1.767$ days) versus the postvaccination period $(2010-2012 ; \mathrm{n}=742$ observations, average value $=0.921$ days), the test result of 8.343 with $\mathrm{df}=946$ was statistically very significant $(p<0.0001$, two sided $)$ with a mean difference of 0.846 days and $95 \% \mathrm{CI}$ of 0.655 to 1.035 days. The same analysis, performed for the non-epidemic period and for the control group, revealed the following t test results. For the non-epidemic period, the 20042006 average absent day value per woman was 0.789 and
0.902 for the 2010-2012 period. T test statistic's value was 1.40 for $\mathrm{df} 1228$, $\mathrm{p}$ value two sided was 0.16 , indicating a non-significant difference. For the control group during the epidemic period, the 2004-2006 average absent day value per woman was 1.896 and 1.330 for the 2010-2012 period. T test statistic's value was 12.542 for $\mathrm{df}$ of 5315 , with a $\mathrm{p}$ value two sided $<0.0001$, indicating a very significant difference. This can be explained by two facts, the high number of observations $(n=6175)$ and the remarkable dip in 5 days of absence from work in 2009 as shown in figure 1C. Linear regression analyses of the average number of absent days by year (2004 to 2012) were undertaken for the two groups in table 2, the target and the control group, during the epidemic period. $\beta$-Coefficients were, respectively, $-0.138(95 \% \mathrm{CI}$ -0.19 to -0.08$)$ and -0.039 (95\% CI -0.07 to -0.01 ). The $t$ test value of -3.887 with $16 \mathrm{df}$ results in a $p$ value two-sided $<0.05$. The null hypothesis, that the slopes are equal, can be rejected, and a significant difference between the two groups for any incremental year in the analysis is present. This may be caused by an external factor such as the introduction of the rotavirus vaccine.

Figure 2A reports the results of table 2, comparing the average value per month and per time period, because the epidemic and non-epidemic seasons have different durations ( 5 and 7 months, respectively). It is important to note that the full cohort of women with vaccinated children does not reach the same absenteeism level as in the non-epidemic period. At the same time, the 
Figure 1 Proportional distribution of days absent from work during the epidemic period reported per year for $(A)$ working mothers with a first child and (B) the control group (women aged 30-35 years); and (C) proportional distribution of days absent from work during the non-epidemic period reported per year for working mothers with a first child.

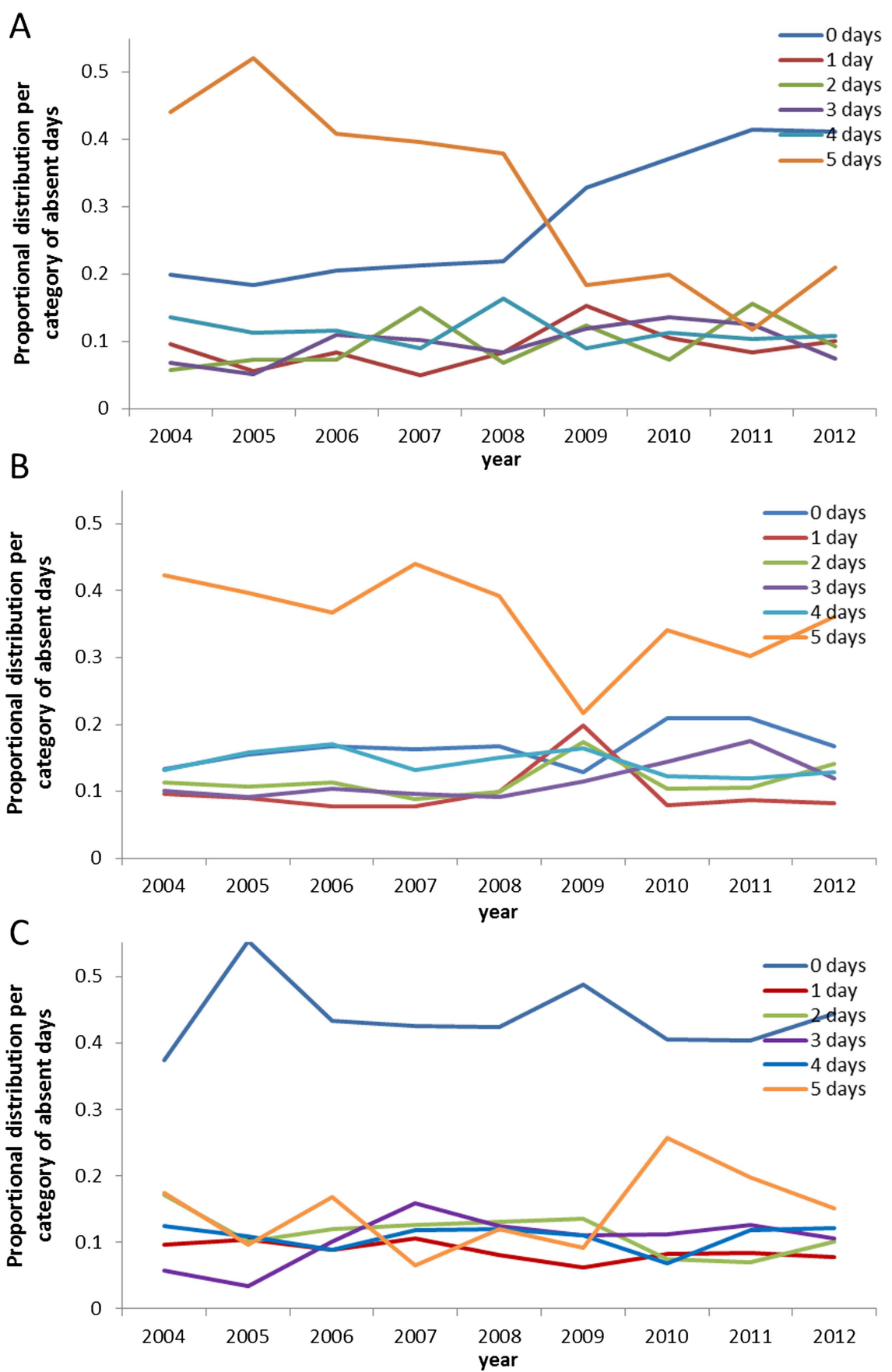

control group does not manifest a substantial decline in absenteeism during the same observation period.

Figure 2B also shows the average number of absent workdays during the epidemic period when the firstborn child is in the first, second and third years of life. It is interesting that the same type of decline in absenteeism is observed in subsequent years as for the first year postpartum analysis. As already mentioned, reductions in absenteeism started after 2008 following the introduction of the RV vaccine by the end of 2006 . A comparison of averages over the whole observation period shows that prior to the introduction of the vaccine, the average number of days absent from work during the epidemic period was an estimated 1.71 days (average value from 2004 to 2008). The average number of days absent from work in the non-epidemic period was 0.83 days (average value from 2004 to 2012). Thus, the estimated difference in absenteeism obtained from switching from no vaccination to vaccination is approximately 0.88 days per working mother with a first child in the first year of life (1.71 to 0.83$), 0.70$ days for 2-year-old children (1.53 to 0.83 ) and 0.67 days for 3 -year-old children (1.50 to 0.83 ).

The accumulated gain over a 3-year period per working mother with a first child during the epidemic period is 2.24 days $(0.88+0.7+0.67)$. The absolute gain is difficult to measure from the database, which reports fluctuating numbers and different lengths of duration 
Figure 2 (A) Average number of short work absences per woman per month for the control group (blue), the full cohort of mothers during the epidemic period (red), and during the non-epidemic period (green) and (B) Average number of short work absences per woman in the full cohort in the first (red), second (blue) and third (yellow) years postpartum during the epidemic period and the non-epidemic period (green).
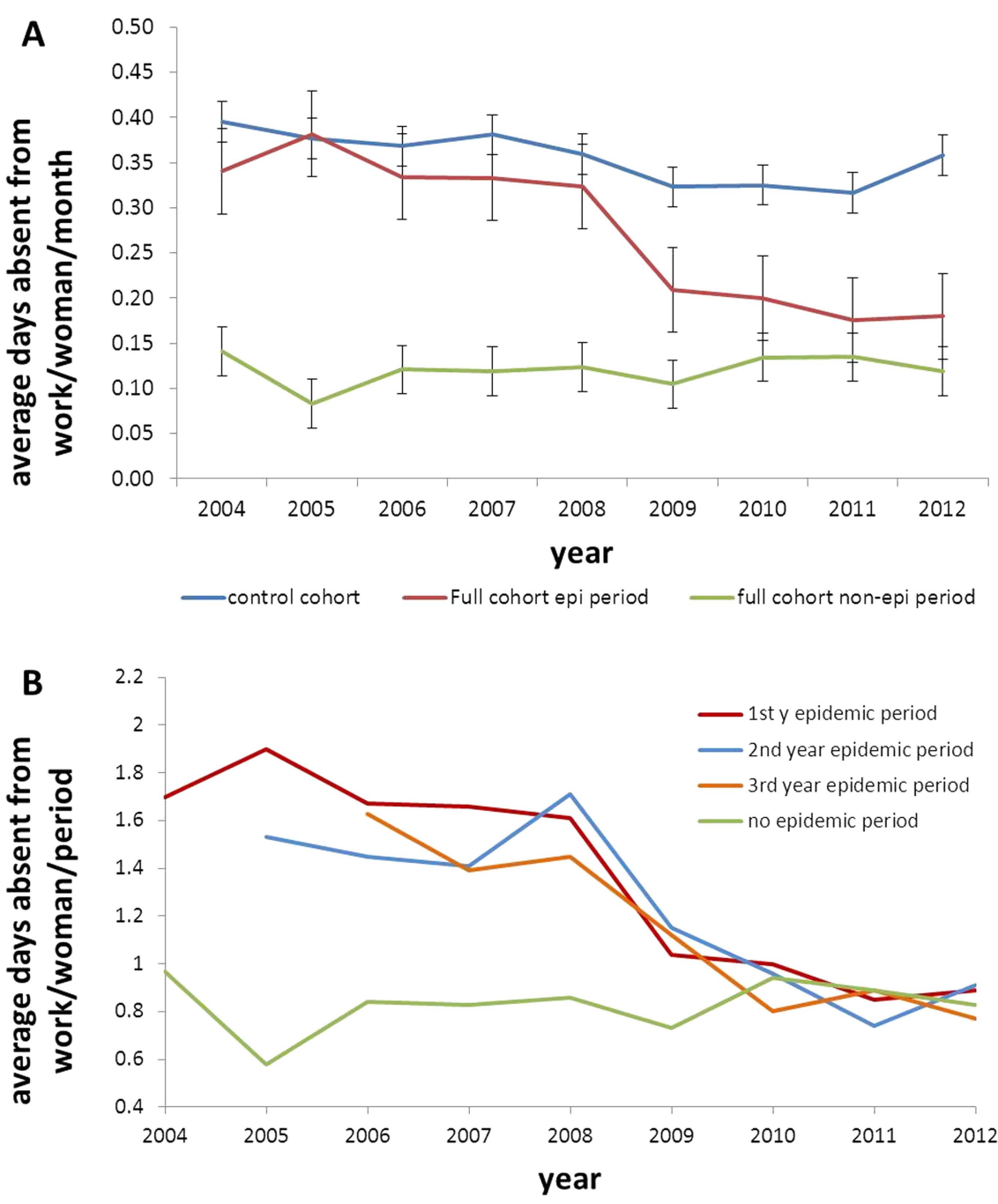

each year. Table 4 shows the calculated values, based on the average numbers obtained.

The benefit of vaccination to an employer with an average annual workforce of 216 working mothers with a first child is an estimated gain of 484 working days over a 3-year period. At an average gross monthly salary of $€ 3000$ ( $€ 135$ per workday), the gross gain is $€ 67095$ for the entire working mother cohort. The employer will spend a total of $€ 26640$ for the vaccine if the cost is an estimated $€ 120$ per mother. This results in an estimated net gain of $€ 40455$ for the cohort, or $€ 187$ per working mother.

\section{DISCUSSION}

The current study investigated whether we could use real-life data to obtain an estimate of the reduction in absenteeism among working mothers when rotavirus vaccination was introduced in Belgium in November 2006 with a high uptake at the start. We compared the observed results with estimates calculated through a simple modelling exercise. The analysis confirms a measurable reduction in work absenteeism observed in the real-life data setting. This reduction was observed among cases with a high number of absentee working days (eg, 5-day absences, see table 2 and figure 1A).

Table 4 Estimated cumulative gain per working mother with a first child over a 3-year period

\begin{tabular}{clllll}
\hline & & $\begin{array}{l}\text { Prevaccination: } \\
\text { days absent from work* }\end{array}$ & $\begin{array}{l}\text { Postvaccination: } \\
\text { days absent from work* }\end{array}$ & $\begin{array}{l}\text { Difference (days) } \\
\text { Postpartum }\end{array}$ & $\begin{array}{c}\text { Days gained } \\
\text { (216 women) }\end{array}$ \\
\hline Average & 1st year & 1.71 & 0.83 & 0.88 & 190 \\
& 2nd year & 1.53 & 0.83 & 0.70 & 150 \\
3rd year & 1.50 & 0.83 & 0.67 & 144 \\
Sum & 4.74 & 2.49 & 2.25 & 484 \\
\hline *Per working woman with a first child. & & &
\end{tabular}


The initial intention of the project was primarily to increase our chances of successfully selecting the right target group to show a difference in absenteeism which could be linked to the introduction of the rotavirus vaccine. Therefore, we opted for mothers with a first child, since in the Belgian culture they are the most likely to take time off work when the child is ill. A reduction in work absenteeism was observed, and the critical question is whether this observed reduction was linked to the introduction of rotavirus vaccination, as many other reasons for short absences from work could cause a fluctuation in this parameter. The analysis here indicates five reasons supporting a potential link between the observed reduction in absenteeism and the introduction of the rotavirus vaccine. First, the reduction happened after the introduction of the vaccine in 2006, at the time we would expect to observe a major reduction during the epidemic rotavirus season. Second, mothers with a first child in their second and third years of life also manifested a reduction in absenteeism starting during the same year (2008), which can be explained by the known herd effect postvaccination. If no herd effect was known for this vaccine, we would not expect to observe these additional reductions in the other age groups at the same period. Third, the observed reduction per working mother closely matches the modelled estimates (see table 3). Fourth, no reduction in work absenteeism was seen during the non-epidemic period, making it unlikely that the reduction in absenteeism resulted from a factor such as a change in rules put in place by the employer to minimise short-term absences, as such a factor would have affected absenteeism during all time periods after 2008. Finally, women with no exposure of their children to any rotavirus vaccination did not show a marked reduction in absenteeism during the same observation period. It is unlikely that the reduction in absenteeism was linked to fluctuations in other childhood infections such as influenza, because there were no reports of high epidemic infectious diseases during the prevaccine periods in the literature or in local disease reports.

Specific conditions in retrospective data analyses must be fulfilled before it is possible to measure the changes observed. Those conditions are: (1) the demographic composition (gender and age) of the study population must remain stable in order to retain the same denominator; (2) the rules and conditions for taking time off work must be maintained; (3) the disease must be causing a serious public health problem over a certain period so that a change in working patterns (eg, absenteeism) can be observed; (4) the new intervention (eg, the vaccine) must have an immediate high uptake as well as a large and rapid impact on the disease; (5) the data registry must be adequate, of high quality, consistent over time and easily stored and accessible and (6) finally, the target population must be a well-defined group. We cannot work with cultural changes over time (eg, fathers instead of mothers suddenly becoming the main carers for young children who fall sick). All these different factors applied to the database of the administrative personnel of the City of Antwerp. For instance, the fact that the data collected on absenteeism was linked to the payment condition of an employee makes the quality of the data very rich. If one of the conditional elements mentioned above is of poor quality, it automatically decreases the value of the whole investigation and the analysis.

Having an initial estimate from the model was a helpful tool in understanding the potential gain to be observed in the real-life database. Looking at all the days of work absences and all mothers with children was not a viable option because the specific condition of interest was lost in the large numbers that were not related to disease in children necessitating short ( $\leq 5$ days) absences from work. Surprisingly, it appeared that the benefit was a little higher in real life than in the model. This could potentially be related to a higher incidence or distribution of the disease than was predicted by the model, or to a herd effect in the vaccinated age group itself. It is clear from the data that a herd effect was realised in other age groups who were unvaccinated when the vaccine was introduced, as reported in figure 2B. The data confirmed our observations in the RotaBIS study, in which the vaccine made a large impact among unvaccinated age groups as soon as it was introduced. ${ }^{3}$

This study has some limitations. First, the sample size of working mothers with a first child was small. However, the analysis was the best we could make in a country where the vaccine coverage rate for rotavirus vaccines was very high from the start. Second, the prevaccination period was short, from 2003 to 2006. This was because the data were only available in electronic format from 2003 onwards, so it was not possible to include earlier years in the analysis. Third, the database did not give a specific reason for absence from work, and therefore it was not possible to identify absences that resulted directly from rotavirus infection of a child. However, as discussed above, our findings are consistent with a link between the reduction in absenteeism and the effect of rotavirus vaccination.

To the best of our knowledge, this analysis is the first to demonstrate a potential effect of the RV vaccine on absenteeism using real-life data. The conditions of RV infection provide the opportunity for this to happen: the disease is very contagious, preferentially affects very young children who need care by an adult, and occurs mainly during a short epidemic season every year at the same time. These conditions allow the comparison of work absenteeism during epidemic and non-epidemic periods. It reinforces the circumstantial evidence showing a link between the observed reduction in absenteeism and the introduction of the vaccine, but we cannot claim or prove a clear causality from the data here. There are potentially other methods for collecting the same data prospectively, but it would be difficult to attain the same quality in the final results. ${ }^{16}$ This is not a 
clinical trial but an analysis of an administrative database, in which the prospect of collecting that type of information in such a rigorous way is not obvious. It should also be clear that the overall benefit of the vaccine on a reduction in absenteeism in the workplace could be greater than measured here in a very specific subgroup of working mothers (those with a first child). It is likely that we could observe the same benefit among working mothers with a second or third child who was never previously exposed to RV.

Finally, will the findings in this particular environment be easily transposable to other settings? Given the many conditions necessary to observe and measure the effect of a vaccine, it is likely that in other settings different amounts of benefit will be seen. For example, the facilities needed for an adult to be easily absent from work for childhood illness must be present before similar results could be observed.

\section{CONCLUSIONS}

Working mothers with a first child benefit from RV vaccination through a reduction in work absenteeism. The modelled estimates and the observed data fit well for absences from work during the year following birth. The higher observed gain (0.88-day vs a 0.72 -day gain) could be explained by a herd effect of the vaccine. There is possibly an underestimate of the total gain as only a select group (mothers with a first child) was investigated. In the case of the City of Antwerp, the benefit can be expressed as a cost gain per woman as a cost-benefit ratio of 1.85 (working days gained/vaccine cost). Confirmation of these results with data sets from other public organisations in Belgium is expected in the near future.

Acknowledgements The authors wish to thank Carla Lefebvre (independent research and writing consultant) and Carole Nadin (Fleetwith Ltd) for assistance in editing this paper; Gregory Collet for his editorial support (Business \& Decision Life Sciences on behalf of GSK Vaccines); and the City of Antwerp for making the data set of administrative personnel available for analysis.

Contributors BS developed the protocol, prepared the analysis, and the report and wrote the first draft of the manuscript. EVdM helped in getting access to the data and reviewed the statistical analysis plan, as well as giving input into the review of the manuscript. VN helped in designing the study and reviewed the different drafts of the manuscripts.

Funding This work was supported by GlaxoSmithKline Biologicals SA (GSK study identifier H0-12-12768). GlaxoSmithKline Biologicals SA was also responsible for all the costs associated with the analysis, as well as the development and publication of the present manuscript. BS received a discount on open access fee due to his second affiliation (University of Groningen).

Competing interests BS is an employee of the GSK group of companies and holds stock in the GSK group of companies. VN reports grants from the GSK group of companies while conducting the study.
Ethics approval The Head of the City Administration of Antwerp.

Provenance and peer review Not commissioned; externally peer reviewed.

Data sharing statement All data were anonymised before sharing among the researchers. The method of analysis and the results were evaluated by all the researchers. Persons who are interested can get access to the data and the method of analysis on request. The anonymised database with information on days and dates of being absent from work and duration, as well as a child's date of birth (MM/YY), was made available per year from 2003 to 2012. All the authors and coauthors have had access to the data. We explained back to the administration personnel how we analysed the data and how we made the link to the data.

Open Access This is an Open Access article distributed in accordance with the Creative Commons Attribution Non Commercial (CC BY-NC 4.0) license, which permits others to distribute, remix, adapt, build upon this work noncommercially, and license their derivative works on different terms, provided the original work is properly cited and the use is non-commercial. See: http:// creativecommons.org/licenses/by-nc/4.0/

\section{REFERENCES}

1. Forster J, Guarino A, Parez N, et al. Hospital-based surveillance to estimate the burden of rotavirus gastroenteritis among European children younger than 5 years of age. Pediatrics 2009;123: e393-400.

2. Soriano-Gabarro M, Mrukowicz J, Vesikari T, et al. Burden of rotavirus disease in European Union countries. Pediatr Infect Dis $J$ 2006;25(1 Suppl):S7-S11.

3. Standaert B, Gomez JA, Raes M, et al. Impact of rotavirus vaccination on hospitalisations in Belgium: comparing model predictions with observed data. PLOS ONE 2013;8:e53864.

4. Plosker GL. Rotavirus vaccine RIX4414 (Rotarix): a pharmacoeconomic review of its use in the prevention of rotavirus gastroenteritis in developed countries. Pharmacoeconomics 2011;29:439-54.

5. Parez N, Giaquinto C, Du RC, et al. Rotavirus vaccination in Europe: drivers and barriers. Lancet Infect Dis 2014;14:416-25.

6. Raes $M$, Strens $D$, Vergison $A$, et al. Reduction in pediatric rotavirus-related hospitalizations after universal rotavirus vaccination in Belgium. Pediatr Infect Dis J 2011;30:120-5.

7. Bilcke J, Beutels P. Reviewing the cost effectiveness of rotavirus vaccination: the importance of uncertainty in the choice of data sources. Pharmacoeconomics 2009;27:281-97.

8. Goossens LM, Standaert B, Hartwig N, et al. The cost-utility of rotavirus vaccination with Rotarix [trade mark] (RIX4414) in the Netherlands. Vaccine 2008;26:1118-27.

9. Jit M, Bilcke J, Mangen MJ, et al. The cost-effectiveness of rotavirus vaccination: comparative analyses for five European countries and transferability in Europe. Vaccine 2009;27:6121-8.

10. Standaert B, Parez N, Tehard B, et al. Cost-effectiveness analysis of vaccination against rotavirus with RIX4414 in France. Appl Health Econ Health Policy 2009;6:199-216.

11. Standaert B, Harlin O, Desselberger U. The financial burden of rotavirus disease in four countries of the European Union. Pediatr Infect Dis J 2008;27:S20-7.

12. Giaquinto $\mathrm{C}$, Van DP, Huet F, et al. Costs of community-acquired pediatric rotavirus gastroenteritis in 7 European countries: the REVEAL Study. J Infect Dis 2007;195(Suppl 1):S36-44.

13. Nakagomi T, Kato K, Tsutsumi $\mathrm{H}$, et al. The burden of rotavirus gastroenteritis among Japanese children during its peak months: an internet survey. Jpn J Infect Dis 2013;66:269-75.

14. Christiaens T, De Loof G, Maloteaux JM. Gecommentarieerd geneesmiddelenrepertorium 2014. 27th edn. Ghent, Belgium: Federaal Agentschap voor Geneesmiddelen en Gezondheidsproducten (FAGG), 2014.

15. Bevers T, Collard A, De Spiegeleire M, et al. De loonkloof tussen vrouwen en mannen in België, 2010. 1st edn. Brussels, Belgium: Belgian Institute for the Equality of Women and Men, 2011.

16. Goossens ME, Rutten-van Molken MP, Vlaeyen JW, et al. The cost diary: a method to measure direct and indirect costs in cost-effectiveness research 2. J Clin Epidemiol 2000;53:688-95. 